\title{
Therapeutic Camps and Their Impact on the Family of Children with Special Health Care Needs: A Mixed Method Study
}

\author{
Brandi Lindsey \\ Middle Tennessee State University, Murfreesboro, TN, USA \\ Email: Brandi.Lindsey@mtsu.edu
}

How to cite this paper: Lindsey, B. (2016) Therapeutic Camps and Their Impact on the Family of Children with Special Health Care Needs: A Mixed Method Study. Open Journal of Nursing, 6, 722-740.

http://dx.doi.org/10.4236/ojn.2016.69074

Received: August 17, 2016

Accepted: September 16, 2016

Published: September 19, 2016

Copyright $\odot 2016$ by authors and Scientific Research Publishing Inc. This work is licensed under the Creative Commons Attribution International License (CC BY 4.0).

http://creativecommons.org/licenses/by/4.0/

\section{Abstract}

Respite care through therapeutic summer day camps is a service used to relieve the physical and mental strains placed on caregivers of children with special health care needs while also creating unique opportunities to benefit the child. The purpose of this study is to determine how respite care in the form of a therapeutic summer day camp for children with special needs impacts a family's ability to manage their child's special health care needs within their family. This research study used mixed methodology combining quantitative data collection through pre- and post-survey and qualitative data collection through interviews that worked to answer questions relating to the effects of a therapeutic summer day camp on parents' perspective and management of their child's condition. The theoretical framework used to guide the study is the Family Management Style Framework. Twenty-two parents completed The Family Management Measure that was administered prior to and at the conclusion of an 8-week therapeutic summer day camp program. Qualitative interviews with 11 parents helped to better understand specific interventions and experiences of the therapeutic camp that benefitted their child and family. Although the quantitative analysis did not yield statistically significant changes in the family's ability to manage their child's condition as a result of attendance at the camp, the qualitative interviews demonstrated robust evidence that the camp provided meaningful experiences for the campers and parents while alleviating stress within the family. Themes include: 1) Family-Child themes of loss of normalcy, relationships affected, increased stress, family adaptations, and love for the child; 2) Camp-Child themes of meeting individual needs, creating happiness, and behavior changes; and (3) CampParent themes of improved perception of the child, decreased stress, parent involvement with staff, and need for specific environment at camp. Implications of the results are discussed, along with recommendations for future research. 


\section{Keywords}

Respite Care, Special Needs, Children, Therapeutic Camps

\section{Introduction}

Children with a chronic illness or disability can encounter many difficulties throughout their lifetimes. Hardships may include physical, mental, developmental, and social issues that not only impact the child but also may increase demands and burdens experienced within the family unit. Caring for a child with a chronic illness or disability can cause many challenges within the family and may contribute to poor family functioning, inadequate management of the child's condition, negative perceptions of the child's disability, and a lack of integration of the child's condition into family life resulting in caregiver burden [1]. Families of children who have a chronic illness or disability may encounter certain issues that make family management more difficult than other families in a typical situation.

These difficulties faced by families of children with chronic disabilities need to be understood, so health care professionals can assist these families in achieving optimal functioning and incorporate strategies into their daily life that increase their ability to manage their child's condition. Because these obstacles can affect the everyday life of the child and family, it is important that support services are identified and understood to meet the needs of these children and their families. Respite care is used to relieve the physical and mental strains placed on caregivers while also creating unique opportunities to benefit the child.

The problem to be addressed in this study is the lack of evidence surrounding the benefits of therapeutic camps as respite care on the family and their ability to manage their child's special health care need. Therapeutic camps have been shown to provide valuable experiences for the child while also meeting the needs of the caregivers [2]-[7]. There is research that supports these outcomes, but there is little evidence that shows how therapeutic camps assist the family in managing their child's special health care needs. There is scant research that identifies the specific components of therapeutic camps as respite care that are meaningful to the families' view of the child and their ability to manage the condition.

The purpose of this study was to explore how respite care in the form of a therapeutic summer day camp for children with special needs influenced a family's ability to manage their child's special health care need within their family. The researcher sought to understand the implications of attendance at a summer therapeutic camp on the parent's perspective of the child's daily life, condition management ability, condition management effort, family life difficulty, view of condition impact, and parental mutuality. These components are all in accordance with the theoretical framework used to guide the study, the Family Management Style Framework [8] and the instrument used in the study, the Family Management Measure (FaMM) [9]. Specific interventions 
and/or experiences at the camp that benefitted the family and improved their management styles were explored through interviewing the parents. The information gathered from the interviews supplemented data obtained through the administration of the FaMM. The researcher also made visits to the camp to gather field notes regarding specific interventions and experiences discussed by the parents in the interviews. The qualitative portion of the data included analysis of the field notes. This added to the understanding of specific interventions and experiences at camp that may assist the parents' ability to manage their child's condition and increase family functioning.

A sequential, exploratory mixed method approach was used to obtain data that explored the effect of a therapeutic summer camp on the family's ability to manage their child's condition. Statistical data were combined with data collected by qualitative interviews to give a more complete understanding of the research purpose.

\section{Research Questions}

The research questions for this study are:

1. In families that have a child with a special health care need, what are the effects of respite care through a therapeutic summer day camp program on parental perceptions in regard to the child's condition?

2. In families that have a child with a special health care need, what are the effects of respite care through a therapeutic summer day camp program on parental perceptions in regard to condition management ability?

3. In families that have a child with a special health care need, what are the effects of respite care through a therapeutic summer day camp program on parental perceptions in regard to the child's condition management effort?

4. In families that have a child with a special health care need, what are the effects of respite care through a therapeutic summer day camp program on parental perceptions in regard to family life difficulty?

5. In families that have a child with a special health care need, what are the effects of respite care through a therapeutic summer day camp program on parental perceptions in regard to the view of the condition's impact?

6. In families that have a child with a special health care need, what are the effects of respite care through a therapeutic summer day camp program on parental perceptions in regard to parental mutuality?

7. Are there differences in the family's ability to manage their child's condition (according to the FaMM) prior to and at the conclusion of the child's attendance at an 8 -week therapeutic summer day camp?

8. What are the perceptions of parents of children with special health care needs of the interventions and experiences at a therapeutic summer day camp program?

9. What interventions or experiences (if any) impacted the parents' perceptions regarding the management of their child's condition?

The specific aims of the researcher are:

1. To understand and evaluate the outcomes that respite care through a therapeutic 
summer day camp program has on family management styles of families of a child with a special health care need.

2. To understand and examine any specific interventions or experiences at camp that assisted parents in improving their perspective of the child's condition on their family life and ability to function as a family.

3. To use the findings to develop specific interventions or create experiences at therapeutic camps that camp organizers can use to promote positive family outcomes and improve family management styles.

\section{Literature Review}

A child's chronic disability or special need may negatively impact the child's emotional, physical, and developmental health. The consequences of a chronic condition in children may include physical disabilities, cognitive and academic deficits, school performance issues, behavioral adjustment, adaptive functioning, and socialization [10]. These changes and disabilities can adversely influence the child's family functioning by increasing family caregiver burden [1]. The family burden encountered after a child's diagnosis of a chronic disability can be related to the stress associated with the management of the child's conditions, perceptions of those close to the child, and the disruption to the normal family processes [11]. Demands placed on the caregiver of a child with special needs contribute directly to both the psychological and the physical health of the caregivers [12]. The family's ability to function affected health directly and influenced the concepts of self-perception, social support, and stress management.

Caring for a child with special health care needs can have an overwhelming impact on all aspects of family life [13]. The family burden that is encountered after a child's diagnosis of a chronic disability can be related to the stress associated with the management of the child's condition, perceptions of those close to the child, and the disruption to the normal family processes [11]. Evidence has demonstrated that families with a child with a chronic illness or disability are at a greater risk for problems with family cohesion, parent-child interactions, problem solving skills, family conflict [14], and lower family functioning [15] [16]. For families of children with special health care needs to function normally, they must be able to integrate their child's condition into daily family life, see their child's life and their family life as normal, and manage their stress through social support [15] [16]. There are many services that seek to provide interventions for these families and children. Respite care is an intervention that can provide valuable support for families and children with special health care needs.

Respite care is identified as a way to alleviate the family's burden of caring for a child with a disability or chronic illness [5] [17]-[20]. Respite care has also been identified as a very positive experience for both the child and the family [13]. Respite care can provide relief from the emotional and physical strains that are prevalent while providing care, and respite care can provide opportunities for the child to gain new experiences and interact socially.

Therapeutic camps are created to give children with special health care needs oppor- 
tunities to participate in activities that other typical children may experience in the camp setting. Activities focus on children's abilities instead of their disabilities. Camps provide children with social interaction and time to experience fun activities that they might not have been able to experience otherwise. Camps can range from overnight weekly camps to day camps in the summer. Counselors are specially trained to meet each child's individual needs. Therapeutic camp programs for children with special needs are unique because they are designed to create goals and experiences for the children with disabilities in order to help them achieve their maximum potential. Therapeutic camps often focus on increasing self-management skills, enhancing emotional adjustment, enhancing self-esteem, and engaging in one-on-one and group social activities [4].

\section{Methods}

An exploratory mixed methods design with a sequential approach was used to collect data. A quantitative instrument titled The Family Management Measure, by [9], was used by the researcher to measure family management styles. This tool does not specifically address the effects of a therapeutic camp on family management styles, so interviews addressing this specific concept were added to the research to explain and augment the findings from the quantitative instrument. Both of these types of data collection complement each other and minimize weaknesses to create robust information regarding the phenomenon being studied. This study occurred over a period of 8 weeks during the summer of 2014.

The quantitative portion of this study used a quasi-experimental, within-subjects design. The FaMM [9] was administered to the same group of participants within 1 week at the start of camp and within 1 week prior to the conclusion of camp. Randomization was not used because the sample consisted of all consenting participants who have children enrolled at the chosen therapeutic camp for the summer of 2014.

The paired samples $t$-test was used to compare the mean differences of the data. The complete analysis of the results of this test is discussed in the analysis section. The instrument scoring of the FaMM was based on a Likert-type Scale with values ranging from 1 to 5 with 1 being Strongly Disagree and 5 being Strongly Agree. Tests for normality were conducted on the pretest and posttest data that also showed normality. The paired sample $t$-test compared the results from the same groups at the appointed time intervals. This analysis yielded no significant changes $(\mathrm{p}>0.05)$ in any of the scales from the beginning of camp to the end of the 8-week camp.

\section{Ethical Considerations}

The researcher followed ethical guidelines by obtaining IRB permission from the researcher's educational institution. The camp director provided a letter of support that indicated his enthusiastic approval for the research to be conducted in the summer camp. The parents were invited to participate and were made aware that there would be no penalty for their child at camp if they chose not to participate. The researcher 
stressed that participation was voluntary, and each parent was given the opportunity to sign the informed consent document. In the observation phase the researcher only observed parents who had signed the informed consent document. Children over the age of 17 were not included in the observations. Children who may have been present in the observation had consent documents signed by their parents. Any observations that occurred with children who were capable of understanding an assent document would have been given the opportunity to sign the form. However, no children met this criterion in the observation, so no assent forms were signed.

\section{Quantitative Instrument}

The measure used for this study derived from the FMS framework was the Family Management Measure [9]. The FaMM is an experiential condition specific measure that includes six family management factors that were identified in a quantitative validation study. These are 1) the child's daily life, 2) the impact of the condition on family life, 3 ) the difficulty of family life, 4) the effort managing the condition, 5) the ability to manage the condition, and 6) parental mutuality [9]. The instrument has 53 items for partnered parents and 45 items for nonpartnered parents. Research was conducted to assess the psychometric properties of the FaMM including factor structure, internal consistency, test-retest reliability, and construct validity [9]. The FaMM was initially tested with 579 parents from 417 families with a wide array of chronic conditions [9]. There were 162 families in the sample that had two parents participating. The parents responded to the 65-item FaMM along with measures of family functioning (Family Assessment Device, child adaptation (Eyeberg Child Behavior Inventory), and child functional status (Functional Status Measure II). In order to evaluate construct validity, hypotheses testing was used and reliability assessment was also completed. The calculations of reliability and validity were modified to account for variations in which both parents were in the home. Based on this analysis, internal consistency reliability for the scales ranged from 0.72 - 0.90. Sixty-five parents were also retested within 2 - 4 weeks, and this retest reliability was calculated at $0.75-0.94$ [9].

The FaMM was developed to understand family management over time and compare family management styles at different points in the child's life while assessing interventions that change the problematic aspects of family management and promote other interventions that strengthen child and family outcomes [9]. The instrument was used for this study to measure how a therapeutic summer day camp for children with special needs affects a family's ability to manage their child's condition. It was also one component used to determine if the camp can be identified as an intervention that promotes optimal child and family outcomes. This measurement was chosen because it was specifically developed to assist the practitioner in understanding how families are able to manage their child's chronic condition. The components of the measurement are directly related to a family's ability to normalize their child and family situation, and it correlates with the items outlined in the Family Management Style Framework. This tool provided a description of each family's management abilities prior to and at the 
completion of camp. This offered the researcher insight into the outcomes that the camp had on the family's ability to manage their child's illness and family life.

\section{Sampling Plan}

The therapeutic camp in which the study was conducted is located in the southeastern region of the United States. This camp is a Christian, summer day camp for children with special health care needs 6 - 25 years of age. The initial contact with families that participated in the research study occurred within the first week of camp. The researcher set up a table near the nurse and camp director at the beginning of the camp day and at the end of the camp day to meet with the parents and discuss the possibility of participation in the research. All of the information in regards to the research was given to the parents of campers at this time. There was a designated room on this hallway that was used for privacy to fill out the questionnaire. As the parents interacted with the nurse and director, the researcher approached them in a friendly manner that invited conversation about the well-being of their child and family. This provided an opportunity for the researcher to explain to the parents about the research study and discuss the consent form. The researcher was present at the table at the close of camp when parents were passing by to pick up their children from the camp. Many of the families know the researcher, so trust was already established. The researcher explained that although she has worked in the camp before, her role would be exclusively to obtain research data throughout the summer camp experience.

At the initial contact with the participants, the researcher presented them with a flyer that explained the importance of the research study and gave a brief description of the procedure for obtaining data. The flyer also contained the researcher's information and goals of the research study along with a discussion of both the qualitative and quantitative portions of the study. If they decided to participate, the researcher then initiated the consent procedure. At this time consent was explained and the consent form was presented. Once parents signed the consent form, the researcher asked if they would like to fill out the questionnaire in a private room at the camp or if they would like to take the questionnaire home with them and return it to camp that week. All parents chose to take the questionnaire home.

In this study convenience sampling was used. Because the number of eligible participants was small, all eligible participants were recruited. Participants came from the same camp to limit confounding variables that may have occurred from including other camps in the area such as differing schedules, types of interventions, and overall environment. Specific inclusion and exclusion criteria were implemented for this study. Purposive sampling was used to recruit participants for the qualitative strand of the study. Prospective participants for the interviews were contacted via phone to describe the interview, discuss the importance of the interview to the study, and establish trustworthiness with the participants. Interviews were conducted on site at the camp after approximately 7 weeks of participation in the camp activities. Interviews were scheduled prior to parents picking up their children or after they were dropped off in the 
morning.

All participants had children enrolled in the chosen respite summer day camp program at least 5 days a week. Inclusion and exclusion criteria included the following characteristics: 1) parents of campers between the ages of 6 and 25 at the time of camp participation; 2) parents were excluded if they have children with a comorbid, possibly terminal illness such as cancer, because this may alter the parent's perspective on the child's condition; 3) families of children with a special health care need must include at least one parent who resides in the same household as the child and speaks English; 4) chronic conditions or disabilities may include autism, down syndrome, cerebral palsy, or any child who has or is at risk for a chronic physical, developmental, behavioral, or emotional condition and requires additional health services; 5) only parents of children between the ages of 6 and 17 may participate in the interviews; 6) only children ages 6 through 17 whose parents had consented may be observed in the camp setting during the field note collection. Only one parent from each household was recruited for participation in the study to complete the FaMM.

\section{Interview Process}

Interviews were conducted on site at the camp after approximately 7 weeks of participation in the camp activities. Interviews were scheduled prior to parents picking up their children or after they were dropped off in the morning. Interviews occurred at the camp site at a convenient time mutually agreed upon with the parents. Permission to use a private room at the camp setting was obtained from the camp director. This room provided a neutral location that was consistently available to each family. In this study only mothers consented to participate in the interviews. Because the researcher had already met all of the parents at the initial meeting and she had worked at the camp before, trust between the researcher and the participants was established. Once consent was obtained for participation, the researcher spent time at the camp interacting with the parents to demonstrate her care and concern for the child and family to continue to build trust.

Interviews were conducted solely by the researcher and were transcribed verbatim by the researcher. Interviews consisted of the researcher and participant being coparticipants. Each interview lasted approximately 30 minutes. The researcher asked the participants to describe their overall experiences of caring for their child within the context of family life. Benefits of camp and specific interventions that occurred at camp were also explored. Guiding questions were used to understand how the child's condition and the attendance at the camp impacted family life.

Prior to the interviews open-ended questions were formulated by the researcher. Open ended questions were developed using the Family Management Style Framework as a guiding principle for question development. The FMSF has three components that are the definition of the situation, management behaviors, and perceived consequences [21]. Through the interviews the researcher sought to assess how these principles are perceived within the family to better understand the family's ability to manage their 
child's condition. A sample of the guiding questions follows:

- How has your child's condition affected your daily life? Your family life? Your social life?

- What are some things that help you manage your child's condition within your family?

- How does the camp help you better manage your child's condition?

- Are there certain experiences at the camp that impact your ability to care for your child's special health care needs?

- How does the camp help you better manage your family?

- What are some specific things that occur at the camp that help you view your child's special need in a different way?

- How does the camp affect your family when camp is over?

- Is there anything else you would like to tell me about how the camp has affected your child and family's ability to manage your child's special needs?

After the interviews began a common thread of parental stress related to the child's condition began to emerge. Applying hermeneutical reasoning along with the expert advice from the dissertation committee, the researcher added the following guiding questions to the interview:

- How does managing your child's condition create stress in your family?

- What aspects of camp (if any) help alleviate the stress surrounding caring for your child?

Once the interviews were completed, some specific interventions that were discussed in the interview process were observed by the researcher in the natural field setting. The field notes were used to complement the interview data.

\section{Results}

\subsection{Sample}

Based on the sampling criteria, 30 primary caregivers from 30 different families were eligible to participate. The final quantitative sample could have included mothers or fathers, but in this study it was mostly mothers (20 mothers, 1 grandmother, and 1 father) who were present at the camp and able to provide consent. The number of diagnosis for each child ranged from 1 to $6(M=2.09)$, and the length of time since diagnosis ranged from 3 years to 23 years or since birth $(M=11.25)$. Demographic data showed 20 participants were Caucasian and 2 participants were African American. The age of parents ranged from 25 years to 73 years $(M=46.6, S D=10.1)$. Twelve of the parents reported other children living in the same home as the child with special health care needs. At the beginning of the study 16 parents indicated they were partnered. In this study partnered was defined as living with a partner in the same household as the child. At the conclusion of the study 17 parents indicated they were partnered. Participant educational levels are as follows: 2 with high school diploma, 1 with technical or trade school, 10 with some college or 2-year degree, 5 with a bachelor's degree, and 3 with a graduate degree with one not reporting. Hours of employment per week are as 
follows: less than 10 hours $=3 ; 11-20$ hours $=2 ; 21-30$ hours $=2 ; 31-40$ hours $=6$; $41-50$ hours $=5$; Over 50 hours $=3$ with one not reporting. Income ranges are as follows: $\$ 10,000$ to $\$ 14,999=1, \$ 15,000$ to $\$ 19,999=2, \$ 25,000$ to $\$ 34,999=1, \$ 35,000$ to $\$ 49,999=3, \$ 50,000$ to $\$ 74,999=5$, Greater than $\$ 75,000=9$ with one not reporting. Parents indicated they spent a range of 4.5 hours a day to 24 hours a day provided care for their child $(M=12.7)$. The participants' children enrolled in the camp were 11 boys and 11 girls ranging in age from 6 years to 23 years of age $(M=13.8)$. For 6 children, it was their first time at camp. The number of diagnosis for each child ranged from 1 to 6 $(M=2.09)$, and the length of time since diagnosis ranged from 3 years to 23 years or since birth $(M=11.25)$. Diagnosis included autism, hydrocephalus, Down Syndrome, developmental delay, PTSD, reactive attachment disorder, seizures, Angelman syndrome, ADHD, craniosynostosis, blindness, Partial Trisomy 18, and Fetal Alcohol Syndrome with a larger number (10) diagnosed with autism. Twelve of the children had siblings ranging in ages from newborn to 23 years. None of the families participated in any other respite care services.

For the qualitative portion, 11 parents consented to participate in the interviews. The interview participants were all Caucasian females and mothers of the campers. The mothers ranged in age from 35 to $57(M=44.5)$. The children (6 boys and 5 girls) ranged in age from $7-17$ years $(M=10.4)$. The children had a variety of diagnosis including autism, developmental delay, seizures, fetal alcohol syndrome, cerebral palsy, and Angelman syndrome. The years passed since the child's initial diagnosis ranged from 4 years to 17 years $(M=9.8)$. Eight parents indicated they were partnered and 8 indicated they had other children living at home. Only one parent indicated it was their child's first time to attend camp. Parents indicated they spent a range of 7 hours a day to 24 hours a day providing care for their child $(M=12.8)$. Participant educational levels are as follows: 1 with high school diploma, 1 with technical or trade school, 4 with some college or 2 year degree, 3 with a bachelor's degree, and 2 with a graduate degree. Hours of employment per week are as follows: less than 10 hours $=2 ; 11-20$ hours $=2$; 21 - 30 hours $=1 ; 31-40$ hours $=2 ; 41-50$ hours $=3$; Over 50 hours $=1$. Income ranges are as follows: $\$ 10,000$ to $\$ 14,999=1, \$ 15,000$ to $\$ 19,999=1, \$ 25,000$ to $\$ 34,999=1, \$ 35,000$ to $\$ 49,999=1, \$ 50,000$ to $\$ 74,999=2$, Greater than $\$ 75,000=5$.

\subsection{Quantitative Results}

For data analysis of the FaMM, each response for the questionnaires was entered into SPSS version 21. Each of the scales was scored according to the instructions provided [9]. These scales included the child's daily life, condition management ability, condition management effort, family life difficulty, view of condition impact, and parent mutuality. In this research study internal consistency was affirmed through the calculation of Cronbach's alpha. Internal consistency values ranged between 0.66 and 0.93 for the scales of the FaMM in this sample as shown in Table 1.

All participants completed the first five scales and 15 of the parents completed the scale on parent mutuality. Analysis included resulting scores for each scale prior to and 
Table 1. Description of Cronbach's Alpha.

\begin{tabular}{|c|c|c|c|}
\hline Scale & $\underline{\text { Number of Items }}$ & $\stackrel{\text { Pretest }}{\text { Cronbach's alpha }}$ & $\begin{array}{c}\underline{\text { Posttest }} \\
\text { Cronbach's alpha }\end{array}$ \\
\hline Child's Daily Life & 5 & 0.73 & 0.66 \\
\hline Condition Management Ability & 12 & 0.87 & 0.74 \\
\hline Condition Management Effort & 4 & 0.68 & 0.89 \\
\hline Family Life Difficulty & 14 & 0.93 & 0.92 \\
\hline Condition Impact & 10 & 0.67 & 0.75 \\
\hline Parent Mutuality & 8 & 0.93 & 0.90 \\
\hline
\end{tabular}

at the conclusion of camp. The alpha level selected for this study was 0.05 . Because the researcher expected the sample size to be small due to convenience sampling, a medium effect size of 0.5 was determined to be adequate. In order for this to occur a sample of 50 was needed for the study. Because the final sample was 22 , the effect size was not met. An effect size of 0.3 could be used for the study with the number of participants, but this would not yield clinically significant results.

The data yielded no significant changes ( $p>0.05$ ) in any of the scales (child's condition, condition management ability, condition management effort, family life difficulty, view of condition impact, and parent mutuality). The small sample size was a threat to statistical conclusion validity. Although this sample was less than the original desired number, it was $73 \%$ of the eligible participants based on inclusion and exclusion criteria and $47 \%$ of the total participants at camp. The researcher chose one camp site in order to control for varying degrees of schedule changes, other activities, and time variations that may be present in other camps. Although the sample was small, it is typical of the variety of special health care needs and disabilities at other camps similar to this one in southeast area of the United States.

One of the most important reasons that the FaMM may not have yielded significant results is that it did not measure any interventions or occurrences that are specific to camp that benefitted the family. The researcher sought to understand what aspects of camp would be meaningful to the participants and determine if camp would affect the family and/or the child in a positive way. After conducting the interviews and analyzing the data, the emerged themes clearly showed that many of the benefits of participating in the camp discussed by the mothers were not specifically addressed by the FaMM.

\subsection{Qualitative Results}

At the conclusion of the coding and categorizing process there were several themes that emerged. The themes for Family-Child categories are: 1) loss of normalcy, 2) relationships affected, 3) increased stress, 4) family adaptations, and 5) love for the child. The themes for Camp-Child categories are: 1) meeting individual needs, 2) creating happiness, and 3) behavior changes. The themes for Camp-Parent categories are: 1) improved perception of the child, 2) decreased stress, 3) parent involvement with staff, 
and 4) need for specific environment at camp. Throughout the interviews each parent discussed a loss of normalcy $(n=11)$ since the child had been diagnosed with a special health care need. This loss was apparent in family life and outside relationships. Participant 20 concluded,

"It affects everything that you do, you know, from your other kids, I mean we have older kids, you know, it affects them, it affects them, we were big campers and stuff and she can't sweat, so we don't do anything outdoors now you know, from every aspect it affects your life."

The loss was evident in the lost dream for a normal family. Participant 18 stated,

"Well you never expect to have a child with special needs, um, that was a tough blow, and then since my boys are older they have been able to help some but they get super frustrated with her autism behaviors, they don't get it, it's just different than what we expected but I guess that is true with any special needs family. Um, I am a lot busier than I expected to be at my age, I am a lot more tired, it s just harder than I expected it be at this stage in my life."

The loss of normalcy theme $(n=11)$ was also discussed within the context of relationships. The mothers expressed a change in their relationships with their friends, spouses, extended families, and other children because of caring for their child. Four of the mothers reported that they had lost the ability to have normal relationships with their friends and families because of their child's condition. This isolation from others was deemed as a loss. Although mothers $(n=7)$ reported a loss of a certain dream for their family, a sense of adaptation, realization, and acceptance of the way their life had turned out with their child was apparent. This life they were living was their reality and they had come to better understand their life with their child and family. Mothers who expressed these ideas had gone through an initial adjustment period with their child's diagnosis and accepted their new "normal" reality with their child. Participant 16 stated, "And then you reach that point of acceptance, and there is still the isolation. So then the gears changed to the acceptance and living with it". Several of the mothers ( $n=$ 4) reported a sense of optimism and hope as they had "gotten better" at caring for their child.

Another recurring problem for these mothers involved making time for their other family members. In the summer months mothers felt there was an added stress because of the constant demands of caring for their child that left them very little time to spend with their other family members. Some mothers $(n=4)$ discussed a sense of guilt over the loss of time with their other children and reported that the other children felt neglected. This added to the mother's stress level because she was unable to divide her time equally.

One of the predominant themes within the Family-Child category was the idea of the family adapting $(n=10)$ to the child's special health care needs. All of the mothers reported they had to learn to adapt in order to have a successful family unit. The predominant categories within this theme include family limitations and modifying the fam- 
ily routine, shared responsibilities, and coping mechanisms. The mothers identified changes they had made in their family that limited what they could do because of the needs of their child. Many mothers reported that certain activities such as camping, hiking, or swimming were no longer part of their family routine because their child could not participate in these activities. There was also a significant modification in the family routine in order to care for their child. Therapy schedules, house design, sleep routines, and other normal activities were modified to meet the needs of the child. Several of the mothers reported that the child's needs came first, so the family had to learn to adapt to the child's needs. Participant 21 stated, "She is paramount, for her wellbeing, her emotional, mental, security well-being." Summer was seen as an especially difficult time because the children were not in school, which created less time for the mothers to have breaks. Every mother did not have the same coping mechanisms, but all mothers reported that they needed breaks in order to decrease stress. For this reason, the therapeutic camp provided much needed respite for the families.

Another category of themes included the benefits from the camp to the child and family. These included: 1) meets individual needs, 2) creates happiness, and 3) behavior changes. The mothers were very consistent in discussing the idea that camp met their child's individual needs $(n=10)$. Every mother stated that their child needed a consistent routine, socialization, and high energy activities to be happy and have their needs met. The camp schedule addressed all of these needs for the child. Most of the mothers indicated that they believed their child enjoyed camp $(n=8)$. Even though some of the children were nonverbal, the mothers felt that they could tell their child looked forward to camp and/or enjoyed being there. Four of the mothers stated that their child became excited and looked forward to attending camp. The mothers concluded that camp made their child happy because it met their needs of socialization, routine, and participation in activities. Participant 20 expressed,

"She is a social butterfly, so she would like let's say the week before camp starts and they are out of school she has to go to work with us, you know, or we split it up, you know, and we will go home with her half a day, she is not happy with that, she likes to be around people, she likes to be involved, and we own our own business, so it's not like we can just take vacation whenever we want and just take her somewhere, so with that, um, honestly I think that that is probably the main thing that camp does. It gives her something to look forward to and gives us something to look forward to in the summer because we don't want her to be bored."

Camp also changed some of the parent's perceptions of their child as they saw them participate in activities and mature in certain areas. Parents appreciated the group activities for their child, Bible stories, and one-on-one interaction of the counselors with the children. They felt that camp met certain needs of their child that they, as mothers, were unable to fulfill. This included the child's high energy needs and participation in other outside activities such as recreation and other group activities. One mother stated, "I was so happy when she got old enough to come to camp". Participant 15 expressed her sadness about camp coming to an end for the summer when she said, 
"And I can't believe next week is the last week, yeah, I hate to see it end. It gives us good memories, and I told my husband that we are going to send (their child) to camp until he ages out of it." We love it. We will be back. We love it. It's just good respite for her and for you and your family-it gives her what she needs." It has been a wonderful thing for her-we wouldn't trust them at a regular day care but we do at camp so that is good-it has been great for her."

Although parents mentioned certain activities their child enjoyed such as swimming, bowling, and Bounce $U$, it was the overall specific camp environment that impacted the parent's perspective of managing their child's needs. The camp staff's love and concern for the child impacted the parents in a positive way. The unique environment of camp geared towards meeting their child's individual needs and focusing on their abilities instead of their disabilities was refreshing to the parents. Participant 21 concluded, "This camp is wonderful, yes, everything, because this camp, they attend to our kid's needs." Participant 22 stated, "This is the only place that knows my kid's needs." This interaction with the camp staff was crucial to the parent's level of decreased stress. Participant 28 commented on how camp affects her view of her child,

"It is for me the activities, the karate, when I can see the pictures where he interacts with ballplayers, on the field trips, hearing how well he does on those things, because these are things that we can't do at home.... being able to see him do things like that that we can't do-those are things-seeing him act like a typical child, he is having a good time and playing-he seems to be able to adapt to this better at camp and I don't get to see him do these things at home."

The parent theme of decreased stress $(\mathrm{n}=10)$ is important to this study because it shows that camp provided a remedy to the theme of increased stress $(\mathrm{n}=10)$ in the discussion of Family-Child themes. The mothers discussed that caring for a child with special health care needs increased stress within their family, but the attendance at camp decreased stress within their family. One of the most prevalent reasons that camp decreased stress was that it filled a void of something for their child to do for the summer and created a specific environment for their child that met their needs while at camp. One mother expressed, "Let me tell you what happened after we started going to camp-I became not desperate, that is what I became because you have to understand from the end of May until August, there is no help." Seven of the mothers directly reported that camp decreased stress for their family. The decrease in stress was a result of extra time for the mothers to participate in other activities and rest, communicating with other parents at camp, relief of parental guilt, extra time to spend with others in the family, and decreased financial burden due to the affordability of camp. Camp also decreased stress because it gave the mothers peace of mind knowing their child was safe and happy at camp.

Throughout the data collection and analysis process, the value of using a mixed methods study became apparent. Based on the findings from the quantitative strand of data collection, the results were not significant, demonstrating no significant improve- 
ments in the parent's perceptions of the child's condition, condition management ability, condition management effort, family life difficulty, view of condition impact, and parent mutuality after attending the summer therapeutic camp for 8 weeks. If this was the only phase of the study, the results would demonstrate no significant benefit from the child's attendance at camp. The researcher was not certain if the FaMM would yield results to measure the true benefits of the camp, so the qualitative strand of data collection was added to the study from the outset, as part of the study design to understand the specific benefits from camp as perceived by the parents. The results from these interviews demonstrated that parents and children indeed benefitted from attending the camp as evidenced by the themes that emerged in the data-collection phase. The results were compared and synthesized to make meaning of the data to formulate recommendations for future research, implications for nursing, camp organizers, and camp staff, and to suggest specific activities and interventions for this camp and other similar camps. This study was unique in comparison to other studies that research the benefits of therapeutic camps because it identified certain interventions that benefitted the child and family. The benefits from the longer duration of the camp also demonstrate the uniqueness of these study results.

\section{Implications for Research}

Both phases of this study provided data that can be used for future nursing research. In regard to the quantitative phase, the FaMM needs to be used in other studies to understand the family's perspective and ability to manage their child's condition. For this study the 8-week time frame for the summer camp was not long enough to demonstrate any statistical significance as measured by the FaMM. The time frame suggested by the researcher for future studies using the FaMM is 6 months to a year with the child completing the entire summer session at the therapeutic camp along with attendance at the respite care days offered throughout the year. Another recommendation for future research includes using a larger sample to increase the power and effect size of the quantitative portion of data collection. The use of a larger camp or several similar camps in the same area may be useful for future research endeavors. Future research should also include questionnaires from both parents with comparisons from each viewpoint in order to see any statistical difference based on the various parent perspectives.

In the future demographic characteristics that are related to parental stress should be examined. Because the idea of stress within the family was a predominant theme in the study, a scale that measures stress along with demographic questions that assess possible stress factors should be included in future research studies with this population. The Parenting Stress Index [22] is a scale that has been used within this population to measure the stress associated with caring for a child with special health care needs [18] [22]. This type of scale along with the use of the FaMM may contribute to a greater understanding of the impact that camp has on the parental stress associated with caring for a child with special health care needs. It may also be beneficial to add components of the themes that emerged from the qualitative strand of data collection to the FaMM. 
This would give quantitative data that are based on the emergent themes from the study.

For the qualitative phase of the study, the data showed that families of children with special needs indeed benefit from a respite therapeutic summer camp. Future research should be aimed at understanding the exact interventions that are meaningful to the parents, the specific training of the counselors, and behavior changes that are apparent within the child as a result of camp. All of these areas were mentioned in the interviews, but they were not fully explored. It would also be beneficial to conduct interviews with both parents to determine the perspective of the father in comparison to the mother. Future interview questions should be developed to determine the specific components of camp that are meaningful for the parents and the child. A sample of these questions includes:

1. What is the difference in the environment at camp vs the environment at school?

2. What does your child learn while at camp?

3. Does camp impact the way you and your partner are able to care for your child's condition?

4. What activities are the most meaningful to your child at camp?

5 . What can be done better at camp to help meet your needs and your child's needs?

6. How do the counselors help your child at camp?

Each of these questions targets a specific area that needs to be further explored to make more specific recommendations for the structure of the camp.

\section{Limitations}

This study was limited by the small number of participants recruited for the quantitative strand based on the inclusion and exclusion criteria. A larger sample that encompasses one or two more camps may be beneficial for future research. Convenience sampling was employed in the quantitative strand of the study; therefore, the results are not generalizable. The fact that mostly mothers filled out the questionnaires and only mothers participated in the interviews is also a limitation of the study. Future research should be aimed at recruiting more fathers and parent pairs to participate in the research. The time frame for the study was also only 8 weeks, which could have contributed to a lack of statistical significance. The camp setting was a nonprofit Christian camp that may diminish the transferability to other camps that are not similar in setting or philosophy. The specific training of the counselors and special needs of the children at camp could also lead to varying results.

\section{Conclusions}

This mixed method study used a sequential design imploring both quantitative and qualitative strands to better understand the perceptions of parents of children with special health care needs after the attendance of a therapeutic summer camp. The researcher also sought to determine the effects of the camp on the parent's perspective in regards to the child's condition, condition management ability, condition management effort, 
parental mutuality, and family life difficulty.

These themes supported the theoretical framework used for this study, the Family Management Style Framework, and they were supported by the current literature surrounding the benefits of respite care. Although the quantitative phase did not yield significant results, the study overall yielded very significant results and provided insight into the lived experiences of parents caring for a child with a special health care need and the effects on their child and family from attending a therapeutic camp. The qualitative phase of the data collection demonstrated important results concerning the positive outcomes of camp for the child, the family, and the parents. The benefits of the camp on the parent's stress level and family management were paramount in the interviews. Camp also benefitted the children through meeting their individual needs, changing some of their behaviors, and creating happiness for them while at camp. Camp was seen as beneficial to the families and children because it met their emotional and social needs while giving the parents time to rest and spend time doing other activities and being with their families.

The results of the study helped provide recommendations for future research and identify camp activities and interventions that were meaningful to parents. These activities can be implemented in other camps to enhance the overall experience for the child and family. Better communication between the parents and staff along with increased time for parents to socialize with other parents at camp was identified as important modifications to future camps. Future research should be aimed at using larger sample sizes and using both qualitative and quantitative data collection techniques to assess the impact of therapeutic summer camps on parental stress.

This population of parents is a very special group that has specific needs that nurses and other health care providers should seek to meet. This research demonstrated their extreme care and compassion for their children as they sought to provide the best care and gave up so much within their families to care for their child. I hope that this research will serve them well and be meaningful to them as I continually strive to offer them better experiences through nursing and respite care. I hope to always look on the positive side of life and never take for granted the things that I hold dear. One mother stated in the interviews,

It has affected our family life, but in a positive way, it brings us together. Oh yeah, there is always a positive side to it too, and it has helped us recognize the needs around us too. It's a humbling experience to have a child with special needs, sometimes you see things differently. So, it definitely has a positive side too.

May we as nurses always look on the positive side and strive each day to "see things differently".

\section{References}

[1] Aitken, M., McCarthy, M., Slomine, B., Ding, R., Durbin, D., Jaffe, MacKenzie, E., et al. (2009) Family Burden after Traumatic brain Injury in Children. Pediatrics, 123, 199-206. http://dx.doi.org/10.1542/peds.2008-0607 
[2] Greenberg, L. (2011) A Multi-Informant Evaluation of a Summer Therapeutic Camp for Children with Special Needs: Parent and Counselor Ratings and Child Self-Report. Dissertation Abstracts International: Section B: The Sciences and Engineering, 71, 5123.

[3] Meltzer, L. and Johnson, S. (2007) Summer Camps for Chronically Ill Children: A Source of Respite Care for Mothers. Children's Health Care, 33, 317-331. http://dx.doi.org/10.1207/s15326888chc3304_5

[4] Michalski, J., Mishna, F., Worthington, C. and Cummings, R. (2003) A Multi-Method Impact Evaluation of a Therapeutic Summer Camp Program. Child and Adolescent Social Work Journal, 20, 53-76. http://dx.doi.org/10.1023/A:1021467503588

[5] Shelton, K. and Witt, P. (2011) Therapeutic Camps as Respite Care Providers: Benefits for Families of Children with Disabilities. Therapeutic Recreation Journal, 45, 17-31.

[6] Swallow, V., Forrester, T. and Macfadyen, A. (2011) Teenagers' and Parents' Views on a Short-Break Service for Children with Life-Limiting Conditions: A Qualitative Study. Palliative Medicine, 26, 257-267. http://dx.doi.org/10.1177/0269216311401947

[7] Woods, K., Mayes, S., Bartley, E., Fedele, D. and Ryan, J. (2013) An Evaluation of Psychosocial Outcomes for Children and Adolescents Attending a Summer Camp for Youth with Chronic Illness. Children's Health Care, 42, 85-98. http://dx.doi.org/10.1080/02739615.2013.753822

[8] Knafl, K. and Deatrick, J. (2003) Further Refinement of the Family Management Style Framework. Journal of Family Nursing, 9, 232-256.

http://dx.doi.org/10.1177/1074840703255435

[9] Knafl, K., Deatrick, J., Gallo, A., Dixon, J., Grey, M., Knafl, G. and O’Malley, J. (2011) Assessment of the Psychometric Properties of the Family Management Measure. Journal of Pediatric Psychology, 36, 494-505. http://dx.doi.org/10.1093/jpepsy/jsp034

[10] Yeates, K., Taylor, H., Walz, N., Stancin, T. and Wade, S. (2010) The Family Environment as a Moderator of Psychosocial Outcomes Following Traumatic Brain Injury in Young Children. Neuropsychology, 24, 345-356. http://dx.doi.org/10.1037/a0018387

[11] Wade, S., Taylor, G., Drotar, D., Stancin, T. and Yeates, K.O. (1998) Family Burden and Adaptation during the Initial Year after Traumatic Brain Injury in Children. Pediatrics, $102,110-116$.

[12] Raina, P., O’Donnell, M., Rosenbaum, P., Brehaut, J., Walter, S.D., Russell, D., Wood, E., et al. (2005) The Health and Well-Being of Caregivers of Children with Cerebral Palsy. Pediatrics, 115, 626-636. http://dx.doi.org/10.1542/peds.2004-1689

[13] Thomas, S. and Price, M. (2011) Respite Care in Seven Families with Children with Complex Care Needs. Nursing Children and Young People, 24, 24-27. http://dx.doi.org/10.7748/ncyp.24.8.24.s27

[14] McClellan, C.B. and Cohen, L.L. (2007) Family Functioning in Children with Chronic Illness Compared with Healthy Controls: A Critical Review. Journal of Pediatrics, 150, 221 223. http://dx.doi.org/10.1016/j.jpeds.2006.11.063

[15] Knafl, K., Deatrick, J. and Havill, N. (2012) Continued Development of the Family Management Style Framework. Journal of Family Nursing, 18, 11-34. http://dx.doi.org/10.1177/1074840711427294

[16] Knafl, K.A., Darney, B.G., Gallo, A.M. and Angst, D.B. (2010) Parental Perceptions of the Outcome and Meaning of Normalization. Research in Nursing and Health, 33, 87-98. http://dx.doi.org/10.1002/nur.20367

[17] Eaton, N. (2008) I Don't Know How We Coped Before: A Study of Respite Care for Children in the Home and Hospice. Journal of Clinical Nursing, 17, 3196-3204. 
http://dx.doi.org/10.1111/j.1365-2702.2008.02630.x

[18] Cowen, P. and Reed, D. (2002) Effects of Respite Care for Children with Developmental Disabilities: Evaluation of an Intervention for at Risk Families. Public Health Nursing, 19, 272-283. http://dx.doi.org/10.1046/j.1525-1446.2002.19407.x

[19] Ling, J. (2012) Respite Support for Children with a Life-Limiting Condition and Their Parents: A Literature Review. International Journal of Palliative Nursing, 18, 129-134. http://dx.doi.org/10.12968/ijpn.2012.18.3.129

[20] Wilkie, B. and Barr, O. (2008) The Experiences of Parents of Children with an Intellectual Disability Who Use Respite Care Services. Learning Disability Practice, 11, 30-36. http://dx.doi.org/10.7748/ldp.11.5.30.s32

[21] Deatrick, J.A., Knafl, K.A. and Walsh, M. (1988) The Process of Parenting a Child with a Disability: Normalization through Accommodations. Journal of Advanced Nursing, 13, 1521. http://dx.doi.org/10.1111/j.1365-2648.1988.tb01387.x

[22] Mullins, L., Aniol, K., Boyd, M., Page, M. and Chaney, J. (2002) The Influence of Respite Care on Psychological Distress in Parents of Children with Developmental Disabilities: A Longitudinal Study. Children's Services: Social Policy, Research, and Practice, 5, 123-138. http://dx.doi.org/10.1207/S15326918CS0502_06

Submit or recommend next manuscript to SCIRP and we will provide best service for you:

Accepting pre-submission inquiries through Email, Facebook, LinkedIn, Twitter, etc. A wide selection of journals (inclusive of 9 subjects, more than 200 journals)

Providing 24-hour high-quality service User-friendly online submission system

Fair and swift peer-review system Efficient typesetting and proofreading procedure Display of the result of downloads and visits, as well as the number of cited articles Maximum dissemination of your research work

Submit your manuscript at: http://papersubmission.scirp.org/

Or contact ojn@scirp.org 